\title{
Impacts Social Media Have on Young Generation and Older Adults
}

\author{
Wenxin $\mathrm{Li}^{1, \dagger}$, Xuantong $\mathrm{Lin}^{2, \dagger}$, Jiani $\mathrm{Wu}^{3, \dagger}$, Wenhan Xue ${ }^{4,}{ }^{*},{ }^{\dagger}$, Junxian Zhang ${ }^{5, \dagger}$ \\ ${ }^{1}$ Grand International School, Qingdao, Shandong, China \\ ${ }^{2}$ Shenzhen Foreign Languages School, Shenzhen, Guangdong, China \\ ${ }^{3}$ Guanghua Academy, Jiading, Shanghai, China \\ ${ }^{4}$ The Cambridge School of Weston, Weston, Massachusetts, the United States \\ ${ }^{5}$ Jinling High School Hexi Campus, Nanjing, Jiangsu, China \\ ${ }^{*}$ Corresponding author. Email: wxue2022@csw.org \\ These authors contributed equally.
}

\begin{abstract}
This review paper aims to find out how people from different age groups will be affected by social media addiction from a developmental perspective, whether people from certain age groups are more likely to have social media addiction problems and why. Recent research mostly focuses on a specific age group, without analysing the effect and reasons based on each age group. This paper will look closely at both the young and older generations while mainly focusing on the factors of young people's social media addiction since they are the largest proportion among the addicted people. According to a review of previous related literature, it turned out that normal social media users won't bother people's daily life, whereas social media addiction could have a serious impact, such as depression and anxiety; young people are more vulnerable to become addicted to social media compare to middle-aged adults and elders. This trend's causes include internal ones, such as low-esteem and low self-control ability, and one external factor, influence from peers. We believe the investigation of how age difference may affect the influence of social media addiction is still insufficient, and more research will be conducted in the future.
\end{abstract}

Keywords: Social media addiction, Young generation, Age difference

\section{INTRODUCTION}

Nowadays, due to the development of technology and the popularization of the network, social media has entered the life of countless families and become one of the most important methods of communication. These online platforms, such as Twitter, Instagram, Weibo, give people the opportunity to build relationships regardless of the actual distance and allow people to freely express their opinions and creativity. However, when the use becomes problematic, it will eventually lead to some severe outcomes, which one of them is social media addiction: people will have the uncontrollable desire of logging in and be willing to spend excessive time and effort on social media, to the extent that it damages one's daily life routine $[1,2]$.

Addiction is when someone takes in certain substance, for example, alcohol, or making certain behavioral patterns, such as gambling, that will activate the reward system in one's brain, giving the person the "pleasure", and reinforce this certain addictive activity to the point it will impair other normal activities [3]. Social media addiction is a behavioural addiction that has similar characteristics to any other addictive substances, such as drugs, alcohol, and cigarettes, including craving, mood modification, tolerance, conflict, withdrawal symptoms, and relapse [4]. Social media addiction can easily create a negative impact on the users' mental health, which includes bringing stress, anxiety, and depression; studies have indicated that the time of social media usage is proportional to the depressive symptoms of high school students in Central Serbia and among young adults in the United States [5, 6]. Also, since people tend to show themselves as having a "perfect" life in front of strangers, other users seeing these contents may feel jealous, having dissatisfaction with their life and creating low self-esteem due to the comparison [7].

Some researchers have discussed the mechanism behind addiction. Social media platforms create a dopamine-inducing environment where retweets, likes, 
and shares can trigger a similar chemical reaction in the brain's reward area as other addictive drugs or behavior $[8,9]$. When the users receive the reward, whether it is a like or a comment to their post, or it is the interesting content they found, it triggers the neurons to produce dopamine and activate the reward pathways, which give the brain the "pleasure" and associate this feeling with the stimuli, in this term the social media; the dopamine will soon disappear after the "pleasure" is experienced, and the brain will start to search for the high dopamine level again, which will cause the urge for the individual to continue using the social media $[8,9]$. Since using social media gives people pleasure with a short delay and only costs little, the users have the incentive for more rewardseeking behaviour [9]. Figure 1 [10] shows the diagram of the social media dopamine cycle.

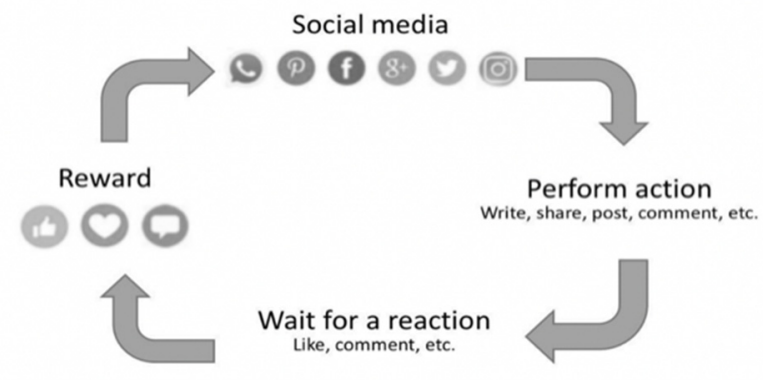

Figure 1. social media dopamine cycle [10]

Although there are many types of research have been conducted on young people and the elders separately, there are not many of which compare the impact social media has on different age groups. We are interested in finding out how the age difference will affect the influence of social media addiction; we are going to reveal the impact social media has on the young generation (teenagers and young adults) and the older generation (middle-aged adults and elders), then compare the results, finding out the age group, which is the younger generation, that is more vulnerable to the social media addiction. We are also going to explain the causes, both internal ones and external ones, of why young people are more likely to have social media addiction.

\section{IMPACTS OF SOCIAL MEDIA ADDICTION}

\subsection{Teenagers and Young Adults}

Many people today, especially the young, are addicted to social media. Some studies have found that the age group of 12-21 uses social media more than any other age group [11]; ninety-three per cent of teens ages 12-17 go online, and 74\% of all adults ages 18 and older go online [12]. It means young people are the main crowd that uses social media and goes online.

Social media has a very big impact on young people today. There are several benefits for social media use: the young may gain communication ability, research ability, and the opportunity for distance learning. For some people, this behavior can satisfy them, give them instant happiness, reduce life conflict, and improve life satisfaction [13]. However, the drawbacks of social media far outweigh its goods; research has determined that social media can indeed lead to physical sub-health and mental issues. First, the overuse of social media can bring young physical stress [14]. Most people tend to stay in one position while playing on their phone or computer. This will solidify their bad posture. When people are engaged in electronic devices, they blink less and for shorter periods, leading to eye strain. Second, when the user becomes addictive, it will bring some mental stress such as depression, distraction, anxiety, and suicide [14]. Also, problematic social media use may also leads to privacy issues; the survey showing in figure 2 [15] found that compared with the past, teenagers publish much more private information about themselves on the Internet, which means that their personal data will be easier to obtain, and few teenagers realize this. When they indulge on the Internet, they hardly consider their own privacy and safety.

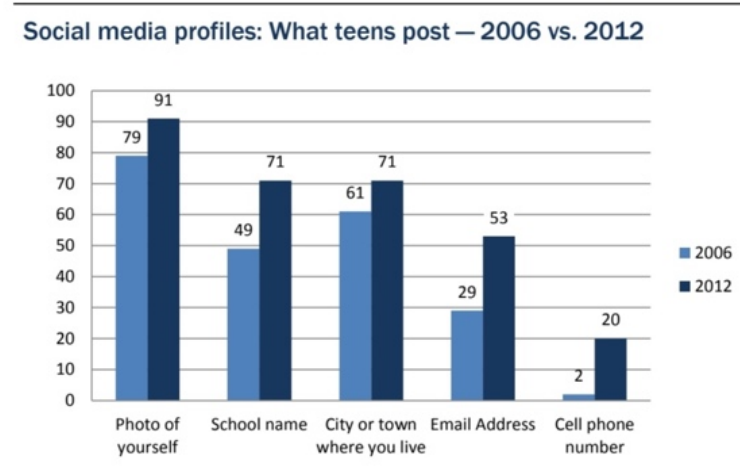

Figure 2. The contents teens post [15]

Some characteristics cause teenagers to be vulnerable to social media addiction. Many reports show that most of the dependence on social media comes from the unique anxiety, desire for performance, desire for selfimprovement, and so on. An interesting survey [16] that divides teenagers who rely on and love social media into five types: teenagers who share their daily life and photos on social media for self-expression; teenagers who use social networks to get information about others, such as stars or people they care about, that is, to track information; teenagers who want to improve themselves and acquire new knowledge; kind-hearted teenagers who like to give advice and help to others after logging in to social networks; there is also self-classification. These people want to find people with a sense of belonging and the same hobbies on social media [16]. On the other hand, it can also be considered from the perspective of the social environment. Contemporary trends may also influence students, and they want to be different or show that they follow the trend to make more friends. This allows them to find ways to express their unique and beautiful side on 
the Internet and always pay attention to the performance of others. At the same time, it is worth mentioning that this kind of psychology is more likely to occur among adolescent girls [17, 18]. According to some data, girls are $9 \%$ higher than the average index for paying attention to their online feedback and spend $26 \%$ more time and energy $[18,19]$. One main reason for social media dependence is the lack of self-control, making it difficult to overcome their desires. Those with low self-control need to struggle directly at doing what they should do and using social media. At this moment, social media has become a temptation. If they use it, they may feel guilty, regretful, and other emotions, coupled with their academic pressure, eventually leading to mental diseases, such as procrastination, depression, or anxiety [19].

Therefore, we believe that teenagers' use of social media still does more harm than good. Therefore, they should reduce and control their use. After all, teenagers are not adults. They do not have good self-control, but they have strong curiosity, social tendency, and a thirst for knowledge, making it difficult for them to adjust themselves, resulting in the most serious dependence and addiction of teenagers to social media.

\subsection{Middle-Aged Adults and Elders}

Social media plays an important role in middle-aged people's daily life. People between the ages of 35 and 44 have relatively stable families and jobs, and they usually need to communicate with their family and working partners by smartphone [20]. As a result, social media not only play a recreational role in the daily life of middleaged people, but they can also help work and strengthen family ties [20]. In addition, a study attempts to figure out whether smartphones can bring job and professional stress to workers [20]. In this study, there are 100 participants (including students and employees from various occupations). The researchers gave them a questionnaire and psychometric stress check. They found that smartphone is necessary for people to help them manage their workload. But with that benefit, many workers have new pressure to virtually connect with friends and family - and those personal contacts that are made possible by social media on smartphones are the source of stress. This idea could prove that stress was associated with personal use of smartphones but not with work. Ironically, the purpose of social media that designer tries to achieve is to bring people close together. However, spending too much time on social media can cause you to feel more lonely and isolated, even exacerbate mental health problems such as anxiety and depression [21].

Social media may bring elders some benefits, such as allowing them to make a connection with others. Keeping social ties with others is important to elders' mental health; however, restricted by their physical conditions and mobility, it is hard for elders to participate in social activities, which may lead to loneliness and dissatisfaction with their lives [22]. Around 43\% of 1604 elders over 65 years old reported that they feel lonely, which is associated with the impairment of health and the increased rate of death $[22,23]$. Social media provide elders with platforms to build connections regardless of the location and time, significantly reducing the sense of loneliness and increasing elders' life quality and mental health [22]. Based on the Pew research center, in 2018, $64 \%$ of elders from age 50 to 64 and $37 \%$ of elders from age 65 and older used social media in the United States [4]. However, the addictive and excessive use of social media can also lead to serious mental issues. In the study conducted by Meshia, Cotten and Bender [4], the researchers surveyed 213 elders that are older than 50, assessed their perceived social isolation and depression, collected the time they spend on social media each day, and used the Bergen Social Media Addiction Scale to test their addictive level; the result turned out that although the estimated time on social media has no direct connection with social isolation, problematic social media use is highly associated with the level of social isolation, which is harmful to one's mental health and can lead to depression [4]. Fortunately, the proportion of elders addicted to social media is much fewer than teenagers; From the survey conducted by CBS in 2017, among Dutch social media users, $28.7 \%$ of people aged from 18 to 24 reported they feel addicted to social media while only $2 \%$ of people aged from 65 or older did so [24]; Based on the survey conducted by Statista in $2019,45 \%$ of Americans aged from 18 to 22 are addicted to social media while $22 \%$ of them aged from 55 to 64 feel addicted [25].

\subsection{Comparison}

Comparing the usage rate of social media among different age groups, we can know that young adults are the most active users of the social media and the group with the fastest-growing rate; the proportion of Facebook users aged from $18-29$ grew from $9 \%$ in 2004 to $84 \%$ in 2013 [26].

On the other hand, for middle-aged adults and elders, social media may provide some important benefits, such as help to maintain family ties, build relationships, and avoid boredom. Still, for teenagers, since they are easier to get addicted, social media plays a harmful role more than a good one, for example bringing stress, anxiety, and suicidal attempts. Why did it happen? We are going to explain the reasons for the differences.

\section{REASONS}

There are myriad reasons behind the differences, and they can be categorized into two main kinds: external and internal factors. 


\subsection{Internal Reasons}

\subsubsection{Eager to pursue or get "likes" on social media}

Neuroscientists have found that those "likes" that are seen on a social media post may be especially intoxicating to growing brains. So to find out why teenagers who have growing brains are more addicted to "likes", a study scans teenagers' brains when they use social media. Scientists from the University of California, Los Angeles claimed that a certain part of the brain connected with rewards hums with activity whenever teens see one of their photos earn lots of "likes" [27], which means that those social media can activate the brain reward system. For instance, when young people say they gain many "likes" of their photos, the social activity and visual center in the brain are lighted up. For older people, although their brain also will be activated by social media, the degree of activation is much less than in adolescents. Past research on the nucleus accumbens shows that compared to kids or adults, teens have exaggerated activity in this area of the brain regarding rewarding activities [27]. So this is one of the reasons that why young people are easier to be addicted to social media.

\subsubsection{Low self-esteem}

Low self-esteem is one of the characteristics of social anxiety, a state of anxiety resulting from the prospect or presence of interpersonal evaluation in real or imagined social settings [28]. Social anxiety is a fast-growing trend that is thought to disproportionately affect young people [29]. As a milder form of social phobia, social anxiety can have debilitating symptoms for people who are faced with social situations. The symptoms often include anxiety, depression, and an overall uncomfortable feeling that influences one's interaction in social situations [30]. Low self-esteem, self-confidence, and self-efficacy are commonly seen characteristics of people with social anxiety. According to Bandura [31], self-efficacy as "the conviction that one can successfully execute the behavior required to produce the outcomes," meaning that people with low self-efficacy might not be able to maintain social relationships successfully; people with low selfconfidence or self-efficacy seldom engage in social activities in reality or have fewer opportunities of engaging in such activities, due to their negative perceptions of their competence in sociability. However, social relationships are indeed an indispensable psychological desire for most human beings. Therefore, people with low self-confidence or self-efficacy need to look for an alternative to fulfil their desire. Studies have shown that those people tend to build more intimate relationships online [32].

\subsubsection{Lack of ability to self-control}

The reason that young people cannot easily control their behaviour is based on risk-taking. A neuroscientist called Adriana Galván [33] at the University of California Los Angeles says that adolescent behaviour surpasses impetuous rebellion or uncontrollable hormones, and risk-taking has caused a lot of the early work on the teenage brain, says Ronald Dahl [33], who studies adolescent brain development at the University of California, Berkeley. Risk-taking is the main factor affecting adolescent behaviour [34], making teens engage in riskier behaviour than older people, including tobacco use, alcohol use, or social media addiction. What's more, some teenagers may engage in self-harm and other forms of violence.

\subsubsection{Leisure boredom}

Leisure boredom is the subjective perception that leisure experiences are not enough to satisfy the optimal arousing of being psychologically rewarding [35]. To put it more simply, leisure boredom is the ambivalent perception of having too much time but too little to do. Teenagers are most likely to experience leisure boredom when a) leisure activities are not challenging or unsatisfactory, and b) they lack the skills to participate in leisure activities [35]. In addition, leisure time is often fragmented, such as when people are waiting in lines or travelling long commutes. Hence, people tend to do something entertaining and stimulating (surfing on social media, for instance) to avoid experiencing leisure boredom [35].

\subsection{External Reason}

\subsubsection{Peers}

Social media is one of the most predominant ways adolescents connect with their existing real-life social networks [36]. One of the reasons is that many teenagers reported that online social interactions through social media are occurring in a private setting [37]. According to LaFotana and Cillessen [38], to be accepted or liked in a group is one of the strongest motives for adolescents' behaviours, and social media can easily provide instant feedback with likes and comments features that relate to teenagers' popularity among peers [39]. Additionally, social media interaction with offline friends enhances the connectedness between teenagers and their peers [40]. Some teenagers feel lonely or rejected when they are the only one who does not engage in a particular activity, prompting them to start doing the same activity to fit in groups and obtain recognition and a sense of belonging [41]. This idea is further reinforced by a study conducted by Steijn in 2014 that demonstrates that peer pressure motivates adolescents to use social media more than it does to people of any other stage [41]. 


\section{CONCLUSION}

In this article, we discussed that people of different age groups are affected by social media to different degrees and in different ways, whether people of specific age groups are more prone to such problems, and the reasons for this phenomenon. After comparing the addictions of different ages, we found that adolescents are the most prone to social addiction at all ages because of their own characteristics, such as social tendency or desire to express themselves. Also, it may be affected by the gender and society environment around them. Furthermore, social media can cause psychological and physical harm, such as headaches, depression or anxiety. We have made these contents as comprehensive and complete as possible and clearly illustrate the influence of social media on people and people's dependence on social media in the contemporary social environment. Both educators and sociologists should notice this problem. These are worthy of the attention of some teenagers, their parents and teachers. Since teenagers tend to have poor self-control and are the most prone to addiction, they should be helped to control social media based on understanding the causes and motivations of addiction, which can be learned from this paper. On the other hand, this phenomenon seems more and more serious in modern society, as more and more people rely on social media to live. Maybe some sociologists or psychologists should pay attention to social media. Maybe in the future, we will see some sort of pattern.

\section{REFERENCES}

[1] Griffiths, M. D. (2000). Internet addiction: Time to be taken seriously? Addiction Research. https://doi.org/10.3109/16066350009005587

[2] Griffiths, M. D. (2012). Facebook addiction: Concerns, criticism, and recommendations: A response to Andreassen and colleagues. Psychological Reports. https://doi.org/10.2466/01.07.18.PR0.110.2.518520

[3] American Psychiatric Association. (2013). Diagnostic and Statistical Manual of Mental Disorders, 5th Edition: DSM-5 (5th ed., Vol. 1). American Psychiatric Publishing.

[4] Meshi, D., Cotten, S. R., \& Bender, A. R. (2019, September 13). Problematic social media use and perceived social ...Problematic Social Media Use and Perceived Social Isolation in Older Adults: A Cross-Sectional Study. https://smnlab.msu.edu/wpcontent/uploads/2019/09/Meshi_2019_Gero.pdf.

[5] Hou, Y., Xiong, D., Jiang, T., Song, L., \& Wang, Q. (2019, February 21). Social media addiction: Its impact, mediation, and intervention. Cyberpsychology. https://cyberpsychology.eu/article/view/11562/1037 3.

[6] Pantic, I., Damjanovic, A., Todorovic, J., Topalovic, D., Bojovic-Jovic, D., Ristic, S., \& Pantic, S. (2012). Association between online social networking and depression in high school students: Behavioral physiology viewpoint. Psychiatria Danubina. https://doi.org/10.1002/mpr.1348

[7] Hunt, M. G., Marx, R., Lipson, C., \& Young, J. (2018, December). No More FOMO: Limiting Social Media Decreases Loneliness and Depression. Guilford Press Periodicals. https://doi.org/10.1521/jscp.2018.37.10.751

[8] Haynes, T. (2021, February 4). Dopamine, smartphones \&amp; you: A battle for your time.Science in the News. https://sitn.hms.harvard.edu/flash/2018/dopaminesmartphones-

[9] MACIT, H. B., MACIT, G., \& GÜNGÖR, O. (2018, June 21). A RESEARCH ON SOCIAL MEDIA ADDICTION AND DOPAMINE DRIVEN FEEDBACK.

https://dergipark.org.tr/tr/download/articlefile/607734

[10] Kotler, S. (2017, February 21). [Video] Porn, Social Media, Alcohol and the chase of dopamine. Youtube. https://www.youtube.com/watch?v=Q4GHVUCcW $4 \mathrm{~A}$

[11] Loebig, B. (2015, August 7). How Does Social Media Affect Youth? www.loebigink.com/howdoes-social-media-effect-youth/.

[12] Pew Research Center. (2020, May 30). Social media and young adults. Pew Research Center: Internet, Science \& Tech. http://www.pewresearch.org/internet/2010/02/03/so cial-media-and-young-adults/.

[13] Reilly, M. O. (2018, July 30). Potential of social media in promoting mental health in adolescents. Health promotion international. https://pubmed.ncbi.nlm.nih.gov/30060043/.

[14] Davis, B. (2021, May 15). How is social media affecting the youth? Mvorganizing.org. https://www.mvorganizing.org/how-is-socialmedia-affecting-the-youth/.

[15] Gasser, U., Madden, M., Lenhart, A., \& Cortesi, S. (2013, May 21). Teens, social media, and privacy. Berkman Klein Center. https://cyber.harvard.edu/publications/2013/teens_s ocialmedia_privacy.

[16] Altuwairiqi, M., Jiang, N., \& Ali, R. (2019). Problematic Attachment to Social Media: Five Behavioural Archetypes. International journal of environmental research and public health, 16(12), 2136. https://doi.org/10.3390/ijerph16122136 
[17] Skogen, J. C., Hjetland, G. J., Bøe, T., Hella, R. T., \& Knudsen, A. K. (2021). Through the Looking Glass of Social Media. Focus on Self-Presentation and Association with Mental Health and Quality of Life. A Cross-Sectional Survey-Based Study. International journal of environmental research and public health, $18(6), \quad 3319$. https://doi.org/10.3390/ijerph18063319

[18] Charmaraman, L. (2021, June 7). Prototyping for social wellbeing with early social Media Users: Belonging, experimentation, AND Self-care: Wellesley centers for women. Prototyping for Social Wellbeing with Early Social Media Users: Belonging, Experimentation, and Self-Care | Wellesley Centers for Women. https://www.wcwonline.org/JournalPublications/prototyping-for-social-wellbeingwith-early-social-media-users-belongingexperimentation-and-self-care.

[19] Du, J., Kerkhof, P., \& Koningsbruggen, G. M. van. (2021, August 4). The reciprocal relationships between social media self-control failure, mindfulness and wellbeing: A longitudinal study. PLOS

ONE. https://journals.plos.org/plosone/article?id=10.1371 \%2Fjournal.pone.0255648.

[20] Scott, S. (2014, Apirl 30). the Psychological Toll of the Smartphone. PsychologicalScience. Retrieved August 12, 2021, from https://www.psychologicalscience.org/observer/the -psychological-toll-of-the-smartphone

[21] Riehm, K. E., Feder, K. A., \& Tormohlen, K. N. (2019, September 11). Associations Between Time Spent Using Social Media and Internalizing and Externalizing Problems Among US Youth. JAMA Network.

https://jamanetwork.com/journals/jamapsychiatry/f ullarticle/2749480.

[22] Coto, M., Lizano, F., Mora, S., \& Fuentes, J. (2017, May 13). Social Media and Elderly People: Research Trends. SpringerLink. https://link.springer.com/chapter/10.1007/978-3319-58562-8_6.

[23] Couture, L. (2012, September 13). Loneliness linked to serious health problems and death among elderly. Taylor $\&$ Francis. https://www.tandfonline.com/doi/full/10.1080/019 24788.2012.708846? scroll=top\&needAccess $=$ true.

[24] Statistics Netherlands (2018, May 18). More and more young adults addicted to social media. Statistics Netherlands. https://www.cbs.nl/en$\mathrm{gb} /$ nieuws/2018/20/more-and-more-young-adultsaddicted-to-social-media.

[25] Statista Research Department (2021, January 28). U.S. social media addiction by age GROUP 2019 . Statista. https:/www.statista.com/statistics/1081292/socialmedia-addiction-by-age-usa/.

[26] Amelia, S. (2014). Exploring the Effects of Social Media Use on the Mental Health of Young Adults. University of Central Florida. Retrieved August 12, 2021, from https://stars.library.ucf.edu/cgi/viewcontent.cgi?arti cle $=2683 \&$ context $=$ honorstheses 1990-2015

[27] Almendrala Anna. (2016, June 3). This Could Explain Why Teens Are So Obsessed With Social Media. Huffpost. Retrieved August 12, 2021, from https:/www.huffpost.com/entry/this-could-explainwhy-teens-are-so-obsessed-with-socialmedia_n_574f7084e4b0ed593f134279

[28] Leary, M. R. (1988). Self-presentational concerns and social anxiety: The role of generalized impression expectancies. In R. M. Kowalski \& C. D. Campbell (Eds.), Journal of Research in Personality (Vol. 22, pp. 308-321).

[29] Jefferies Philip, Ungar Michael, 2020. Social anxiety in young people: A prevalence study in seven countries. Plos One. https://journals.plos.org/plosone/article?id=10.1371 /journal.pone.0239133

[30] Pierce Tamyra. (2009, November). Social anxiety and technology: Face-to-face communication versus technological communication among teens. ScienceDirect. Retrieved August 12, 2021, from https://www.sciencedirect.com/science/article/abs/p ii/S0747563209000971

[31] Bandura, A. (1977). Self-efficacy: Toward a unifying theory of behavioral change. Psychological Review, 84(2), 191-215. https://doi.org/10.1037/0033$295 \times .84 .2 .191$

[32] Jeong, E. J., \& Kim, D. H. (2011). Social activities, Self-efficacy, Game attitudes, and game addiction. Cyberpsychology, Behavior, and Social Networking, 14(4),

213-221. https://doi.org/10.1089/cyber.2009.0289

[33] Telzer, E. H., Fuligni, A. J., Lieberman, M. D., \& Galván, A. (2014, May 6). Neural sensitivity to eudaimonic and hedonic rewards differentially predict adolescent depressive symptoms over time. PNAS. Retrieved September 20, 2021, from https://www.pnas.org/content/111/18/6600.

[34] Smith Kerri. (2018, February 21). Sex and drugs and self-control: how the teen brain navigates risk. Nature. Retrieved August 12, 2021, from https:/www.nature.com/articles/d41586-01802170-3

[35] Chen, C., \& Leung, L. (2016). Are you addicted to Candy Crush Saga? An exploratory study linking psychological factors to mobile social game addiction. Telematics and Informatics, 33(4), 11551166. https://doi.org/10.1016/j.tele.2015.11.005 
[36] Valkenburg, P. M., \& Peter, J. (2009). Social consequences of the Internet for ado- lescents: a decade of research. Current Directions in Psychological Science, 18, 1e5. http://dx.doi.org/10.1111/j.1467-

8721.2009.01595.x.

[37] Gross, E. F. (2004). Adolescent internet use: what we expect, what teens report. Journal of Applied Developmental Psychology, 25, 633 e649. http://dx.doi.org/ 10.1016/j.appdev.2004.09.005.

[38] LaFontana, K. M., \& Cillessen, A. H. N. (2010). Developmental changes in the priority of perceived status in childhood and adolescence. Social Development, 19, 130e147. http://dx.doi.org/10.1111/j.14679507.2008.00522.x.

[39] Košir, K., Horvat, M., Aram, U., Jurinec, N., \& Tement, S. (2016). Does being on facebook make me (feel) accepted in the classroom? The relationships between early adolescents' facebook usage, classroom peer acceptance and self-concept. Computers in Human Behavior, 62, 375-384. https://doi.org/10.1016/j.chb.2016.04.013

[40] Quinn, S., \& Oldmeadow, J. (2013). The Martini effect and social networking sites: early adolescents, mobile social networking and connectedness to friends. Mobile Media \& Communication, 1, $237 \mathrm{e} 247$. http://dx.doi.org/10.1177/ 2050157912474812.

[41] Steijn, W. M. P. (2014). A developmental perspective regarding the behaviour of adolescents, young adults, and adults on social network sites. Cyberpsychology: Journal of Psychosocial Research on Cyberspace, 8, $68 \mathrm{e} 82$. http://dx.doi.org/ 10.5817/CP2014-2-5. 